\section{Kidney \\ Blood Pressure Research}

\title{
Early Exercise Training After Renal Transplantation and Asymmetric Dimethylarginine: The Effect of Obesity
}

\author{
Vladimír Teplan ${ }^{\mathrm{a}}$ Andrea Mahrova ${ }^{\mathrm{b}}$ Jan Pit'hac Jaroslav Racek ${ }^{\mathrm{d}} \quad$ Robert Gürlich $^{\mathrm{e}}$ \\ Vladimír Teplan Jre Ivo Valkovsky ${ }^{f}$ Milena Štollova ${ }^{a}$
}

aDepartment of Nephrology, Transplant Centre, Institute for Clinical and Experimental Medicine and Institute for Postgraduate Education; ' $F$ Faculty of Physical Education and Sport, Charles University; ${ }^{c}$ Cardiovascular Research Centre, Institute for Clinical and Experimental Medicine, Prague; 'Institute of Clinical Biochemistry and Hematology, Medical Faculty, Charles University, Pilsen; eDepartment of Surgery, $3^{\text {rd }}$ Medical Faculty, Charles University, Prague; ' Department of Internal Medicine, Medical Faculty, Ostrava University, Ostrava, Czech Republic

\section{Key Words}

Renal Transplantation • Physical Exercise • ADMA • Obesity

\begin{abstract}
Background/Aims: To assess, in a prospective cohort study of 238 renal transplant patients, our hypothesis that elevated ADMA levels may be influenced by physical exercise and obesity. Methods: Blood samples before and after six months were obtained from 116 transplant patients participating in an aerobic exercise (Group I). A control group consisted of 122 matched transplant patients who did not exercise regularly (Group II). Results: There were no significant differences in ADMA levels between both groups before the training program (Group I $\mathrm{I}_{B}$ vs Group II $\mathrm{I}_{B}$ ). After six months of exercise, ADMA levels in Group I decreased (Group $I_{B}$ vs Group $I_{A}: 3.50 \pm 0.45$ vs $2.11 \pm 0.35 \mu \mathrm{mol} / L_{;} p<0.01$ ) and were lower compared to those in Group II (Group I $\mathrm{A}_{\mathrm{A}}$ vs Group II $: 2.11 \pm 0.23$ vs $3.25 \pm 0.34 \mu \mathrm{mol} / \mathrm{L} ; \mathrm{p}<0.01$ ). Analysis of our results in obese renal transplant recipients $\left(B M I \geq 30 \mathrm{~kg} / \mathrm{m}^{2}\right.$ ) confirmed a smaller effect of exercise training (Group $I_{B O}$ vs Group $I_{A O}: 3.75 \pm 0.52$ vs $3.45 \pm 0.45 ; p<0.05$ and Group $I_{A O}$ vs Group $\mathrm{II}_{\mathrm{AO}}: 3.45 \pm 0.45$ vs $\left.3.74 \pm 0.62 ; \mathrm{p}<0.05\right)$. Blood lipids, $\mathrm{HbA}_{1 c^{\prime}}$ insulin, and systolic BP were also affected by the training program. Conclusion: Elevated ADMA levels were significantly decreased by early exercise after renal transplantation. The effect of exercise was smaller in obese patients.
\end{abstract}




\section{Kidney \\ Blood Pressure Research}

Kidney Blood Press Res 2014;39:289-298

\begin{tabular}{l|l}
\hline DOI: 10.1159/000355806 & (C) 2014 S. Karger AG, Basel
\end{tabular}

Published onlıne: August 27, 2014

www.karger.com/kbr

\section{Introduction}

Patients after renal transplantation are at a particularly high risk of metabolic disorders and cardiovascular disease. Endothelial dysfunction may be linked to increased circulating concentrations of the endogenous NO synthase inhibitor asymmetric dimethyl L-arginine (ADMA) as a demonstrable marker of endothelial dysfunction [1, 2].

Increased levels of ADMA are partially caused by renal impairment, with the levels remaining elevated after renal transplantation. This may be because of the persistent decrease in the rate of ADMA degradation (presumably to impaired activity of enzyme dimethylarginine dimethylaminohydrolase [DDAH] in the kidney) [3].

In non-transplant and transplant patients, plasma ADMA concentrations were higher in obese insulin-resistant individuals, and weight loss was associated with a significant decrease in plasma ADMA levels [4, 5].

Elevated ADMA concentrations are associated with increased cardiovascular risk [6]; and raised ADMA levels predict cardiovascular events in patients with renal failure [7]. Patients after kidney transplantation experience endothelial dysfunction and higher ADMA concentrations than healthy persons, which may contribute to the high cardiovascular morbidity in this population [8].

In chronic renal failure and after renal transplantation, adipose tissue secretes numerous hormones and cytokines considered to be major players in fat-related insulin resistance and endothelial dysfunction [9-12]. Weight gain after renal transplantation can be a risk factor for the patients' and graft outcome [13-15].

Regular physical training has been shown to improve endothelium-dependent vasodilation and the cardiovascular risk profile in patients with cardiovascular risk factors [16]. Exercise can positively influence endothelial dysfunction in chronic kidney disease and in patients on dialysis. However, there are few relevant data of an effect of exercise on ADMA levels in patients after renal transplantation [17].

The purpose of our study was to characterize and evaluate the plasma levels of ADMA in renal transplant recipients before and after a period of early regular physical exercise and in obesity.

We hypothesized that raised ADMA levels may be significantly affected by regular aerobic exercise.

\section{Materials and Methods}

This study was approved by the Human Ethics Review Committee of the Institute for Clinical and Experimental Medicine (Prague, Czech Republic), and complies with the Declaration of Helsinki, including its current revisions and Good Clinical Practice Guidelines. The procedures used were in accordance with institutional guidelines. All subjects gave their written informed consent before enrollment into the study.

\section{Study subjects}

Our prospective cohort study included 116 patients ( 68 males and 48 females; mean age $58 \pm 7$ years; range 25 to 71 years; median age, 54.0 years) undergoing their first cadaveric renal transplantation at the Transplant Center of the Institute for Clinical and Experimental Medicine (Prague, Czech Republic) since January 1, 2012 who had agreed to participate in a supervised aerobic exercise program for six months.

A control group consisted of 122 (60 males and 62 females) renal transplant patients matched for age, sex, HLA typing, duration of previous dialysis, history of cardiovascular disease and immunosuppression regimen who did not exercise regularly and did not participate in the training program.

Collection of patient data was completed by October 31, 2013. Patients were examined by the Clearance Laboratory of the Division of Metabolism at the Department of Nephrology (Transplant Center, Institute for Clinical and Experimental Medicine, Prague, Czech Republic) up to 6 months after renal transplantation. Blood samples were obtained 2 weeks after surgery and after 6 months. Renal function was assessed using inulin and creatinine clearance. 


\section{Kidney \\ Blood Pressure Research}

Kidney Blood Press Res 2014;39:289-298

\begin{tabular}{l|l}
\hline DOI: $10.1159 / 000355806$ & (c) 2014 S. Karger AG, Basel
\end{tabular}

Published online: August 27, 2014

www.karger.com/kbr

Obesity

The long-term, standard triple-drug immunosuppression protocol included regimens based on cyclosporin A (Sandimmun Neoral, Novartis, Basel, Switzerland) or FK506-tacrolimus (Prograf, Astellas, Prague, Czech Republic), mycophenolate mofetil (Cellcept, Hoffmann-La Roche, Basel, Switzerland) and steroids (Prednisone, Zentiva, Prague, Czech Republic). Patients with episodes of graft rejection were excluded from the study.

Four of the 116 exercising patients and six of the 122 non-exercising patients were diagnosed to have diabetes mellitus, and were treated with insulin. There were no acute cases of infections at the time of the baseline examination (4 weeks before blood sampling).

Patients with a recent history of recent cardiovascular events (within the last 12 months) were excluded, those eligible for inclusion had to be non-smokers for at least 3 years. All patients were regularly treated with angiotensin-converting enzyme inhibitors, angiotensin receptor blockers, and statins based on the results of blood pressure measurement and laboratory examination. Using the standard Subjective Global Assessment Scoring Sheet, an experienced dietitian performed individualized dietetic intervention. At their first outpatient follow-up visit, patients were advised to consume 1-1.2 g/kg/day of protein and 30 $\mathrm{kcal} / \mathrm{kg} /$ day during the first post-transplant year.

\section{Evaluation of physical fitness and regular exercise regimen}

Physical fitness was evaluated using the Senior Fitness Test (SFT). Health-related quality of life (HRQOL) was assessed using the standardized SF-36 questionnaire comparing, first, patients data with those of the general population and, second, after the exercise program (pre-/post-tests).

The renal transplant recipients in the exercising group participated in the 6-month training program of stationary cycling. Each exercise session lasted for 1 hour, with the workload progressively increased on an individual basis. Following a 3-5-minute warm-up, resistance was increased until achieving a heart rate of $60-70 \%$ of the previously established difference from resting to maximum heart rate. This workload was maintained over 40 minutes, followed by a 5-minute cool-down. During the first two weeks, training took place twice a week to be increased to three times a week during the remaining study period. All training sessions were guided and supervised by a physician. The patients were allowed to perform an additional training program at home, but compliance with the supervised training sessions had to be $>60 \%$ for study eligibility. The non-exercising transplant controls were not attending any training program.

The protocol had two parts, one including diagnostic functional tests, with the other containing intervention-related issues. The entry part designed to determine current functional status includes the Senior Fitness Test (SFT) developed by Rikli-Jones, and determining motor performance (joint mobility, muscular strength, motor skills and coordination, dynamic stability, and cardiorespiratory endurance). The second part of the protocol was the SF-36 questionnaire designed to assess the effect of exercise training on quality of life. The intervention part included a 2-week adaptation phase, a 10-week development phase, and a 12-week maintenance phase (already in the home setting), complemented by assessment performed by a specialist in kinetic anthropology (functional muscle tests and exercise training).

Anthropometric examination, sampling, and clearance methods

Anthropometric examination of patients was performed in the basal state, at the beginning and end of the study. The height and weight of all subjects were measured and their BMI was calculated. Blood samples for hormonal measurement were taken in the basal state before surgery and at 12 months post-transplant. Renal function was estimated in the Clearance Laboratory of the Department of Nephrology (Transplant Center, Institute for Clinical and Experimental Medicine, Prague, Czech Republic) using an inulin clearance technique $\left(\mathrm{C}_{\text {in }}\right)$ and corrected creatinine clearance $\left(\mathrm{C}_{\mathrm{cr}}\right)$ technique. For $\mathrm{C}_{\text {in }}$ determination to be accurate, it is critical to achieve a balanced state of plasma inulin concentration for the urine collection period. To secure a sufficiently large urine volume, patients drank 0.5 to $1.0 \mathrm{~L}$ of water 1 hour before the investigation. The renal clearance of inulin was measured at plasma inulin levels of between 20 to $30 \mathrm{mg} \%$; this was achieved by an initial i.v. load and subsequent maintenance infusion. With longer (60minute) urine collection periods, blood samples were collected at the beginning, in-between and at the end of the period. Creatinine clearance measurement involved a precise urine collection over 24 hours with 2 venous blood samples at the start and end of the collection period. 


\section{Kidney Blood Pressure Research}

Kidney Blood Press Res 2014;39:289-298

\begin{tabular}{l|l}
\hline DOI: $10.1159 / 000355806$ & (c) 2014 S. Karger AG, Basel
\end{tabular}

Published onIIne: August 27, 2014

www.karger.com/kbr

\section{Blood chemistry}

Blood samples were collected into evacuated tubes with ethylenediaminetetraacetic acid, and the blood was immediately centrifuged. All patients fasted for at least 10 hours before sampling to avoid an effect of methionine from food on ADMA levels. For ADMA quantification, an enzyme-linked immunoassay method (ADMA kit, ELISA, DLD Diagnostika GmbH, Hamburg, Germany) and an AUTO-EIA II microplate reader (Labsystems Oy, Espoo, Finland) were used. This competitive method uses the microtiter plate format. The ADMA is bound to the solid phase, and ADMA in samples is acylated and competes with the bound ADMA for a fixed number of rabbit anti-ADMA antiserum binding sites. Afterward, equilibrium-free antigen and free antigen-antiserum complexes are removed by washing. The bound antibody is detected by anti-rabbit peroxidase and 3.30,5.50-tetramethylbenzidine as a peroxidase substrate. The final product of this reaction is monitored at $450 \mathrm{~nm}$. The amount of antibody is inversely proportional to the ADMA concentration of the sample. Inulin (polyfructosane S) was analyzed using anthrone on a spectrophotometer at a wavelength of 580 nm (Antelie Light Secoman, Domond Cedex, France).

Total cholesterol, HDL-cholesterol and triglycerides were determined using an enzymatic colorimetric method with an Olympus AU 600 analyzer and reagents from Olympus Diagnostics, GmbH (Hamburg, Germany). LDL-cholesterol was calculated using Friedewald's formula. Serum insulin concentrations were measured using a commercial RIA kit (CisBio International, Lyon, France); glycated hemoglobin ( $\mathrm{HbA}_{1 \mathrm{c}}$ ) was analyzed using liquid chromatography on a Tosoh HLC-723 G7 analyzer (Shiba, Minato-Ku, Tokyo, Japan) and 24-h proteinuria by photometry with pyrogallol red using an Olympus 800 system (Hamburg, Germany).

\section{Statistical analysis}

SigmaStat software (SPSS Inc., Chicago, IL, USA) was used for statistical analysis. A $t$-test or MannWhitney rank sum test was employed to compare data from the two groups of renal transplant patients. The relations between the respective variables were assessed using Pearson's or Spearman's correlation coefficient as appropriate. Results were considered statistically significant at a $p<0.05$.

\section{Results}

Basic clinical and biochemical characteristics of exercising and non-exercising renal transplant patients are listed in Table 1.

Both groups did not differ significantly with respect to age, gender or renal function measured by inulin and creatinine clearances. After six months of regular exercise training, patients in Group I had significantly lower serum levels of ADMA (Group $\mathrm{I}_{\mathrm{B}}$ vs Group $\mathrm{I}_{\mathrm{A}}: 3.50 \pm$ 0.45 vs $2.11 \pm 0.35 \mu \mathrm{mol} / \mathrm{L} ; p<0.01$ ) and there were also significant differences as compared

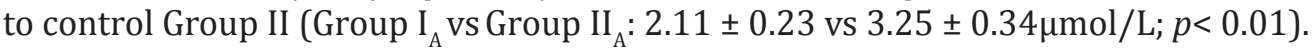

After 6 months of regular exercise, slightly significant differences were observed in the levels of $\mathrm{HbA}_{1 c^{\prime}}$ insulin, cholesterol, LDL-cholesterol, triglycerides, and systolic blood pressure in Group I ( $p<0.05)$. Patients in non-exercising Group II showed a significant increase in BMI and waist circumference as against exercising Group I (Group $\mathrm{I}_{A}$ vs Group $\mathrm{II}_{\mathrm{A}} ; p<0.02$ ).

During the six months of follow-up, renal function as measured by inulin and creatinine clearances was increased $(p<0.01)$.

Table 2 summarises the clinical and biochemical characteristics of exercising and nonexercising obese renal transplant recipients $\left(\mathrm{BMI} \geq 30 \mathrm{~kg} / \mathrm{m}^{2}\right)$. The number of obese patients in the exercising group during the follow-up period rose only slightly (from 22 to 38, Group $\mathrm{I}_{\mathrm{BO}}$ vs Group $\mathrm{I}_{\mathrm{AO}}$ ) compared to higher rise seen in the non-exercising one (from 24 to 54, Group $\mathrm{II}_{\mathrm{BO}}$ vs Group $\mathrm{II}_{\mathrm{AO}}$ ) and there were significant differences between both groups (Group $\mathrm{I}_{\mathrm{AO}} \mathrm{VS}$ Group $\mathrm{II}_{\mathrm{AO}} ; p<0.02$ ). Analysis of our results in obese renal transplant recipients (BMI $\geq 30$ $\mathrm{kg} / \mathrm{m}^{2}$ ) confirmed a small yet significant effect of exercise training (Group $\mathrm{I}_{\mathrm{BO}}$ vs Group $\mathrm{I}_{\mathrm{AO}}$ : $3.75 \pm 0.52$ vs $3.45 \pm 0.45 ; p<0.05$ and Group $\mathrm{I}_{\mathrm{AO}}$ vs Group $\mathrm{II}_{\mathrm{AO}}: 3.45 \pm 0.45$ vs $3.74 \pm 0.62$; $p<0.05)$. 


\section{Kidney \\ Blood Pressure Research}

Table 1. Clinical and biochemical characteristics of all exercising and non-exercising transplant subjects. Exercising transplant subjects in the first month after transplantation with stabilized renal function (Group $I_{B}$ ) and 6 months after tranining (Group $I_{A}$ ). Control group of non-exercising subjects in the first month after transplantation with stabilized renal function (Group II $_{B}$ ) and after six months of follow-up (Group II $_{A}$ )

\begin{tabular}{|c|c|c|c|c|c|c|}
\hline Parameter & Group I B & Group $\mathrm{II}_{\mathrm{B}}$ & Group $I_{A}$ & Group $\mathrm{II}_{\mathrm{A}}$ & $\begin{array}{c}\text { Stat.sign. } \\
\text { Gr I } I_{B} \text { vs } \\
\text { Gr I I }\end{array}$ & $\begin{array}{c}\text { Stat.sign. } \\
\text { Gr I } I_{A} \\
\text { vs Gr II } I_{A}\end{array}$ \\
\hline Number of pts & 116 & 122 & 108 & 118 & NS & NS \\
\hline Gender (M/F) & $68 / 48$ & $60 / 62$ & $64 / 44$ & $57 / 61$ & NS & NS \\
\hline Age (ys) & $58 \pm 7$ & $55 \pm 8$ & $56 \pm 6$ & $55 \pm 8$ & NS & NS \\
\hline BMI $\left(\mathrm{kg} / \mathrm{m}^{2}\right)$ & $26.2 \pm 3.3$ & $25.6 \pm 2.6$ & $28.6 \pm 4.2$ & $31.0 \pm 4.1$ & $\mathrm{p}<0.05$ & $\mathrm{p}<0.02$ \\
\hline Waist circumference (M/F cm) & $92 \pm 6 / 88 \pm 7$ & $90 \pm 5 / 87 \pm 9$ & $94 \pm 8 / 90 \pm 7$ & $102 \pm 7 / 100 \pm 5$ & $\mathrm{p}<0.05$ & $\mathrm{p}<0.02$ \\
\hline $\mathrm{C}_{\text {in }}\left(\mathrm{mL} / \mathrm{min} / 1,73 \mathrm{~m}^{2}\right)$ & $28.6 \pm 10.2$ & $30.2 \pm 8.4$ & $60.1 \pm 8.7$ & $58.2 \pm 8.0$ & $\mathrm{p}<0.01$ & NS \\
\hline $\mathrm{C}_{\mathrm{cr}}\left(\mathrm{mL} / \mathrm{min} / 1,73 \mathrm{~m}^{2}\right)$ & $32.4 \pm 7.4$ & $32.4 \pm 7.4$ & $74.2 \pm 6.6$ & $68.4 \pm 7.4$ & $\mathrm{p}<0.01$ & NS \\
\hline ADMA $(\mu \mathrm{mol} / \mathrm{L})$ & $3.50 \pm 0.45$ & $3.30 \pm 0.52$ & $2.11 \pm 0.35$ & $3.25 \pm 0.34$ & $\mathrm{p}<0.01$ & $\mathrm{p}<0.01$ \\
\hline Cholesterol (mmol/L) & $5.4 \pm 1.4$ & $5.8 \pm 1.6$ & $5.4 \pm 2.2$ & $5.9 \pm 0.4$ & $\mathrm{p}<0.05$ & NS \\
\hline LDL-cholesterol (mmol/L) & $3.9 \pm 1.1$ & $3.6 \pm 1.6$ & $2.6 \pm 1.9$ & $3.5 \pm 0.2$ & NS & NS \\
\hline HDL - chol.(mmol/L) & $1.1 \pm 0.2$ & $1.0 \pm 0.3$ & $1.2 \pm 0.2$ & $1.2 \pm 0.1$ & NS & NS \\
\hline Triglycerides (mmol/L) & $3.8 \pm 1.6$ & $3.5 \pm 1.3$ & $2.8 \pm 1.0$ & $3.4 \pm 1.2$ & $\mathrm{p}<0.05$ & NS \\
\hline HbA1c (\%) & $5.3 \pm 1.4$ & $4.8 \pm 1.2$ & $4.2 \pm 1.2$ & $5.0 \pm 1.3$ & $\mathrm{p}<0.05$ & NS \\
\hline Insulin $(\mathrm{pg} / \mathrm{mL})$ & $365 \pm 40$ & $242 \pm 30$ & $292 \pm 49$ & $320 \pm 56$ & $\mathrm{p}<0.05$ & NS \\
\hline Proteinuria $(\mathrm{g} / 24 \mathrm{~h})$ & $1.2 \pm 0.4$ & $1.0 \pm 0.3$ & $0.8 \pm 0.2$ & $1.1 \pm 0.3$ & NS & NS \\
\hline Systolic BP (mmHg) & $138 \pm 12$ & $142 \pm 8$ & $135 \pm 7$ & $138 \pm 10$ & $\mathrm{p}<0.05$ & NS \\
\hline Diastolic BP (mmHg) & $90 \pm 10$ & $94 \pm 7$ & $90 \pm 6$ & $87 \pm 7$ & NS & NS \\
\hline
\end{tabular}

Table 2. Clinical and biochemical characteristics of obese exercising (Group $\mathrm{I}_{\mathrm{BO}}$, Group $\mathrm{I}_{\mathrm{AO}}$ ) and obese non-exercising ( GroupII $_{\mathrm{BO}}$, GroupII $_{\mathrm{AO}}$ ) transplant patients (BMI $>30 \mathrm{~kg} / \mathrm{m} 2$ ). Obese exercising transplant subjects $\left(\mathrm{BMI} \geq 30 \mathrm{~kg} / \mathrm{m}^{2}\right.$ ) with stabilized renal function before (Group $\mathrm{I}_{\mathrm{BO}}$ ) and 6 months after tranining (Group $\mathrm{I}_{\mathrm{AO}}$ ). Control group of obese non-exercising subjects with stabilized renal function before (Group $\mathrm{II}_{\mathrm{BO}}$ ) and after six months of follow-up (Group $\mathrm{II}_{\mathrm{AO}}$ )

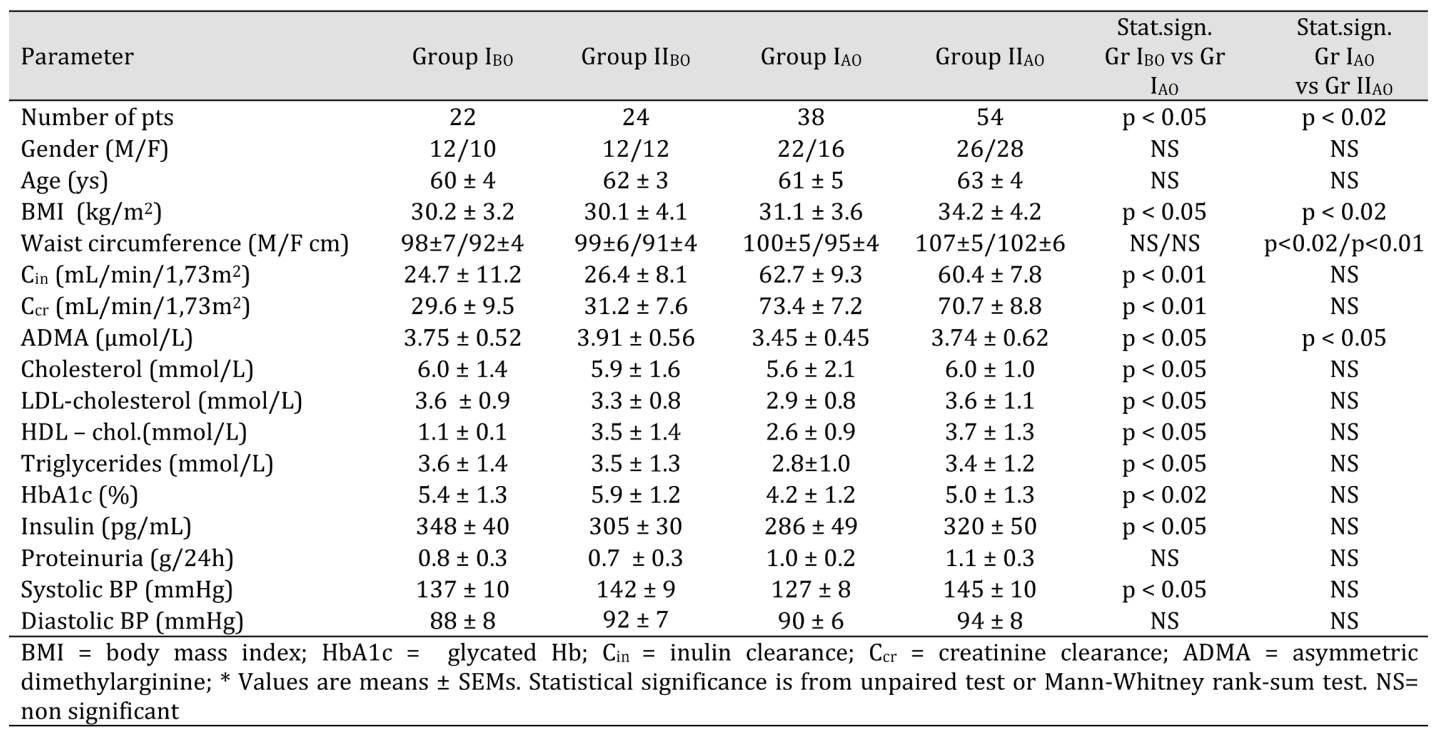

The values of ADMA in obese individuals decreased only slightly at 6 months $(p<0.05)$ compared to non-obese patients $(p<0.01)$. There were slightly significant changes in cholesterol, LDL-cholesterol, and triglycerides $(p<0.05)$ as well as in HbA1c $(p<0.05)$, 


\section{Kidney Blood Pressure Research}

Fig. 1. Laboratory characteristics of ADMA in Group I (exercising) and Group II (non-exercising) transplant subjects in the beginning (Group $I_{B}$ and Group $\mathrm{II}_{\mathrm{B}}$ ) and after six months (Group I and Group $\mathrm{II}_{\mathrm{A}}$ ).

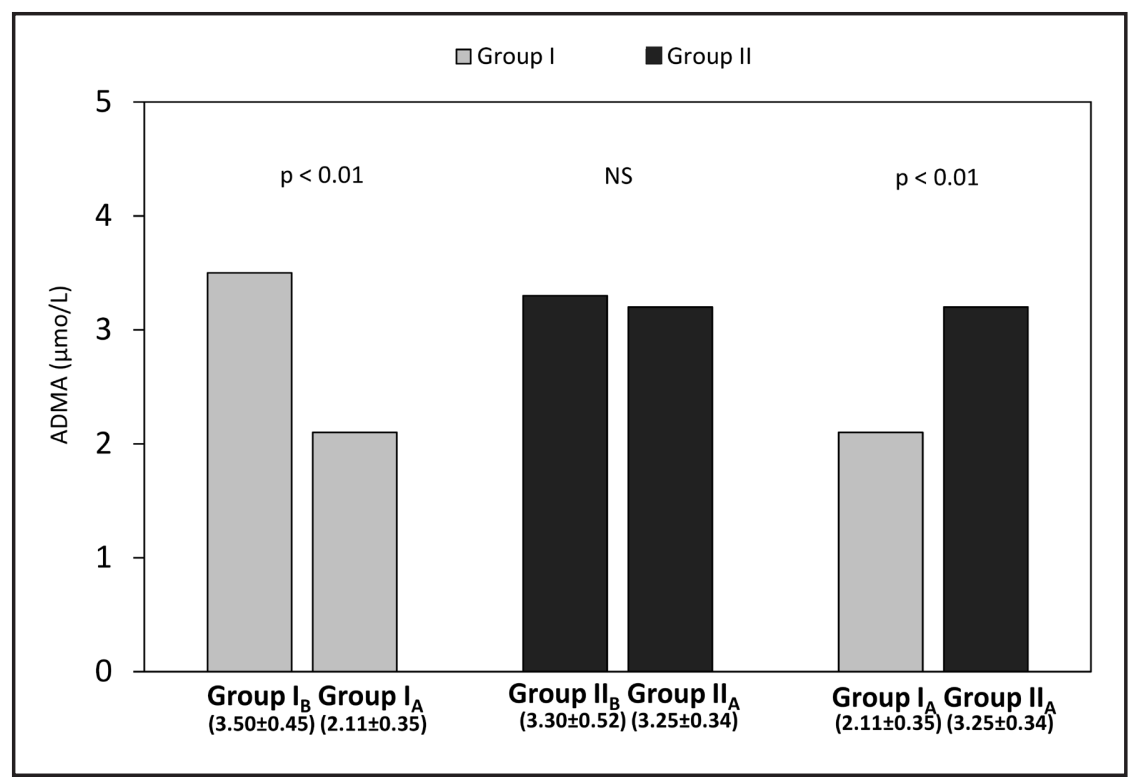

Fig. 2. Laboratory characteristics of ADMA in obese $\left(\mathrm{BMI} \geq 30 \mathrm{~kg} / \mathrm{m}^{2}\right)$ transplant subjects in Group IO (exercising) and Group IIO (non-exercising) in the beginning (Group $\mathrm{I}_{\text {во }}$ and Group $\mathrm{II}_{\mathrm{BO}}$ ) and after six months (GroupI $_{\mathrm{AO}}$ and Group $\mathrm{II}_{\mathrm{AO}}$ ).

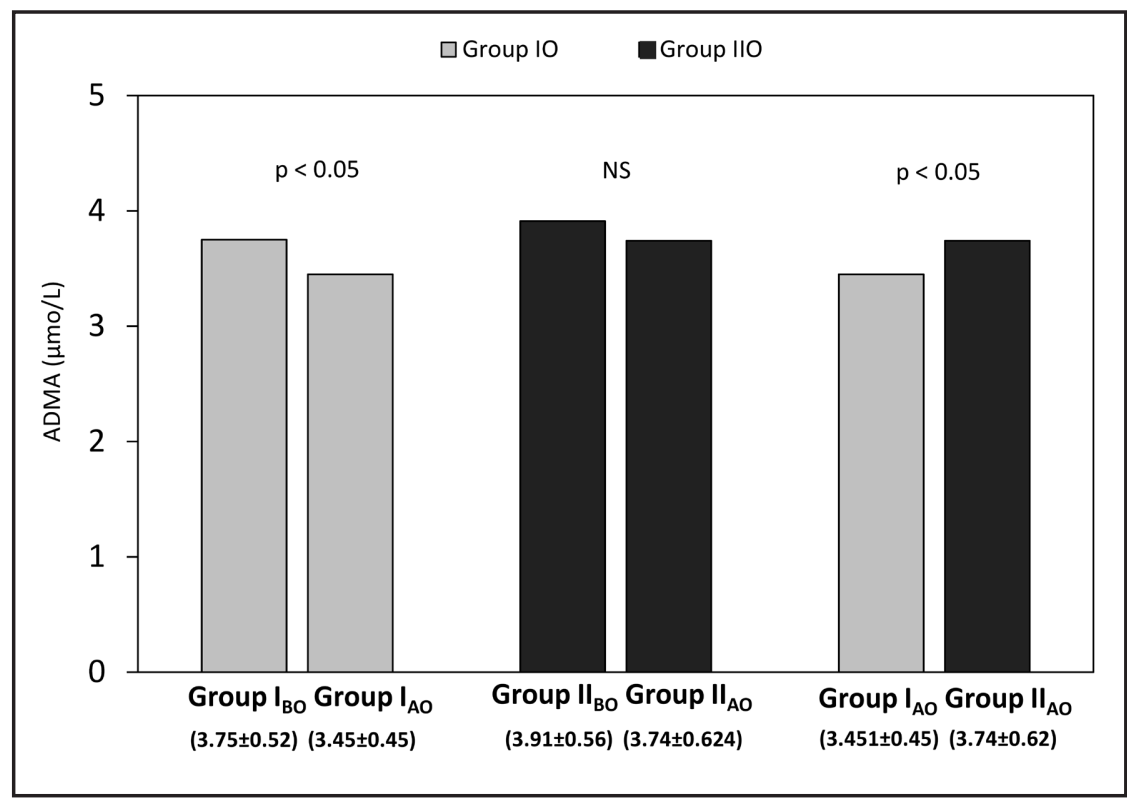

insulin ( $p<0.02)$, and systolic blood pressure $(p<0.05)$ in the exercising group (Group $\mathrm{I}_{\mathrm{B} 0}$ vs Group $\left.\mathrm{I}_{\mathrm{AO}}\right)$. Significant increases in BMI and waist circumference were found both in men ( $p<$ $0.02)$ and women $(p<0.01)$.

Changes in ADMA levels before and after exercise and in the non-exercising group are shown in Fig 1. We confirmed a significant decrease in ADMA levels after six months in the exercising group (Group $I_{B}$ vs Group $I_{A}$ ). There were differences in both groups after six months of follow-up (Group $\mathrm{I}_{\mathrm{A}}$ vs Group $\mathrm{II}_{\mathrm{A}} ; p<0.01$ ).

Figure 2 shows the changes in ADMA levels in obese transplant patients before and after the exercise training program and in the control group. There were only minor differences in the obese exercising group (Group $\mathrm{I}_{\mathrm{BO}}$ vs Group $\mathrm{I}_{\mathrm{AO}} ; p<0.05$ ) and between the exercising and non-exercising obese groups (Group $\mathrm{I}_{\mathrm{AO}}$ vs Group $\mathrm{II}_{\mathrm{AO}}$ ) after six months. No changes were

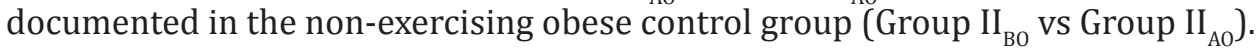




\section{Kidney Blood Pressure Research}

Kidney Blood Press Res 2014;39:289-298

\begin{tabular}{l|l}
\hline DOI: 10.1159/000355806 & (C) 2014 S. Karger AG, Basel
\end{tabular}

Published online: August 27, 2014

www.karger.com/kbr

Obesity

The decrease in ADMA levels in the exercising obese group after six months (Group $\mathrm{I}_{\mathrm{A} 0}$ )

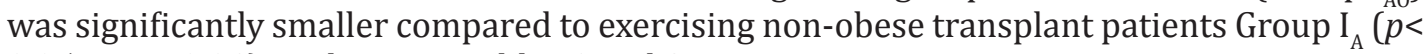
0.05 vs $p<0.01$ ) as shown in Tables 1 and 2 .

\section{Discussion}

Physical training has been shown to improve endothelium-dependent vasodilation and the cardiovascular risk profile in patients with cardiovascular risk factors. Regular physical exercise can also have a beneficial effect on endothelial dysfunction in chronic kidney disease and in patients on dialysis.

The present study demonstrates that elevated ADMA levels decrease in patients after kidney transplantation during a regular program of aerobic exercise for six months; however, the effect of training on ADMA levels could be transient and disappear after termination of the physical exercise program [16]. Non-exercising renal transplant recipients showed higher plasma ADMA levels compared to exercising renal transplant patients. In obese renal transplant patients (BMI $\geq 30 \mathrm{~kg} / \mathrm{m}^{2}$ ) exercising for 6 months, ADMA levels were higher and the effect of regular exercising was significantly decreased. Compared with healthy persons, patients after renal transplantation have a higher number of comorbidities, and their vascular endothelial function is impaired [7]. The raised ADMA levels in our study cohort could be a marker or mediator of reduced basal NO production that could be improved by aerobic exercise [18]. A reduction of ADMA levels by regular aerobic exercise, as seen in our study, could thus possibly contribute to cardiovascular risk reduction in renal transplant recipients.

Interestingly, normalization of ADMA levels was detectable in the absence of changes in conventional risk factors or glucose metabolism $[19,20]$. In addition, the increase in ADMA levels after cessation of the exercise program suggests that ongoing training is critical to maintain of a low cardiovascular risk profile [16]. Nevertheless, validation of the assumption that reduced ADMA concentrations are associated with reduced cardiovascular morbidity requires a longer observation period with clinical endpoints [21].

In the human body, ADMA is produced in large amounts by methylation of proteinbound L-arginine by protein methyltransferases (PRMT). Degradation of ADMA by dimethylaminohydrolase (DDAH) seems to determine ADMA concentrations, alongside with renal excretion which is thought to be a less important way of elimination [22]. Symmetric dimethylarginine (SDMA) is not metabolized by DDAH and is eliminated only by the kidneys [23]. The mechanisms behind exercise-induced ADMA reduction cannot be directly identified from our results. It is not likely that changes in renal function, which is also related to endothelial function, account for the altered plasma ADMA levels, because inulin and creatinine clearances remained within the normal range in transplant patients and did not differ at the end of the observation period. There is evidence that training may affect the antioxidant status through increased expression of the potent radical scavenger superoxide dismutase [24-26].

Obesity and weight reduction were associated with changes in endothelial function. A clinical study demonstrated reduced NO-dependent vasodilation in obese compared with lean subjects. It is possible that increased concentrations of ADMA could contribute to the development of endothelial dysfunction in obesity [13, 19,27].

Dietary changes cannot be excluded as a reason for the increase in ADMA, because our obese subjects in the control group (Group II) reduced their calorie intake slightly without 


\section{Kidney \\ Blood Pressure Research}

Kidney Blood Press Res 2014;39:289-298

\begin{tabular}{l|l}
\hline DOI: $10.1159 / 000355806$ & (C) 2014 S. Karger AG, Basel
\end{tabular}

Published onlıne: August 27, 2014

www.karger.com/kbr

changing the composition of their diet. However, increased carbohydrate intake is associated with reduced plasma ADMA concentrations whereas protein and fat intake seems to have no effect on ADMA [28].

The absence of improved glycemic control is consistent with previous results showing that physical activity does not automatically improve glycemic control in patients after renal transplantation not receiving a controlled diet [29]. Blood lipids slightly improve after six months of training and no significant association with ADMA could be found implying that changes in ADMA are independent of these parameters, and this finding is consistent with data reported from several other studies [30].

There are conflicting data on the effect of angiotensin-converting enzyme inhibitors and angiotensin receptor blockers, but oral antidiabetic drugs (e.g., metformin or glitazone) do improve insulin resistance and reduce ADMA levels. This effect likely results from DDAH up-regulation [29-31]. The study design did not allow to compare the effects of cyclosporine A- and tacrolimus-based regimes. Earlier data suggest that calcineurin inhibitors induce endothelial dysfunction in renal transplant patients, probably by suppressing NO synthesis $[32,33]$. However, according to our results, ADMA levels were significantly higher in obese patients after renal transplantation, although the immunosuppression regimens were similar in both groups. A likely explanation of the discrepancy may involve significant differences in fat mass [34]. The development of proteinuria after kidney transplantation could also be partly linked to endothelial dysfunction with increased levels of ADMA (after excluding the recurrence of glomerulopathies) [35].

The limitation of our study is the absence of chronic renal disease in single-kidney obese and non-obese control patients without immunosuppressive therapy in the exercising and non-exercising regimens.

\section{Conclusion}

Elevated ADMA levels significantly decreased after six months of regular exercise training program in patients after their first cadaveric renal transplantation. In obese renal transplant recipients, the effect of exercise was smaller suggesting that visceral obesity may contribute to endothelial dysfunction and cardiovascular risk factors after transplantation.

\section{Disclosure Statement}

None of the authors declares a conflict of interest in relation to this study and disclose any potential financial conflicts.

\section{Acknowledgments}

The study was supported by grant NT/13139-2/2012 awarded by the Internal Grant Agency of the Czech Republic and by a project supported by MHCZ - DRO (Ministry of Health, Czech Republic, Institute for Clinical and Experimental Medicine - IKEM, IN 00023001) institutional support. 


\section{Kidney \\ Blood Pressure Research}

Kidney Blood Press Res 2014;39:289-298

\begin{tabular}{l|l}
\hline DOI: $10.1159 / 000355806$ & (C) 2014 S. Karger AG, Basel
\end{tabular}

Published onlıne: August 27, 2014

www.karger.com/kbr

Teplan et al.: Exercise After Renal Transplantation, Asymmetric Dimethylarginine and Obesity

\section{References}

1 Kielstein JT, Boger RH, Bode-Boger SM, Frölich JC, Haller H, Ritz E, Fliser D: Marked increase of asymmetric dimethylarginine in patients with incipient primary chronic renal disease. J Am Soc Nephrol 2002;13:170176.

2 Zoccali C, Kielstein J: Asymmetric dimethylarginine: a new player in the pathogenesis of renal disease? Curr Opin Nephrol Hypertens 2006;15:314-320.

3 Lu TM, Chung MY, Lin CC, Hsu CP, Lin SJ: Asymmetric dimethylarginine and clinical outcomes in chronic kidney disease. Clin J Am Soc Nephrol 2011;6:1566-1572.

-4 Krzyzanowska K, Mittermayer F, Kopp H-P, Wolzt M, Schernthaner G: Weight loss reduces circulating asymmetrical dimethylarginine concentration in morbidity obese women. J Clin Endocrinol Metab 2004;89:6277-6281.

-5 Meier-Kriesche HV, Arndorfer JA, Kaplan B: The impact of body mass index on renal transplant outcomes: a significant independent risk factor for graft failure and patient death. Transplantation 2002;73:70-74.

6 de Mattos AM, Prather J, Olyaei AJ, Shibagaki Y, Keith DS, Mori M, Norman DJ, Becker T: Cardiovascular events following renal transplantation: role of traditional and transplant-specific risk factors. Kidney Int 2006;70:757-764.

7 Fazalzadeh A, Mehdiazadeh A, Ostoran MA, Raiss-Jalalli GA: Incidence of cardiovascular risk factors and complications before and after kidney transplantation. Transplant Proc 2006;38:506-508.

-8 Yilmaz MI, Saglam M, Caglar K, Cakir E, Ozgurtas T, Sonmez A, Eyileten T, Yenicesu M, Acikel C, Oguz Y, Ozcan O, Bozlar U, Erbil K, Aslan I, Vural A: Endothelial functions improve with decrease in asymmetric dimethylarginine (ADMA) levels after renal transplantation. Transplantation 2005;80:1660-1666.

-9 Axelsson J, Heimbürger 0, Lindholm B, Steinvinke IP: Adipose tissue and its relation to inflammation: the role of adipokines. J Ren Nutr 2005;15:131-136.

$\checkmark 10$ Zoccali C, Mallamaci F, Tripepi G: Adipose tissue as a source of inflammatory cytokines in health and disease: focus on end-stage renal disease. Kidney Int 2003;63:S65-S68.

11 Weisberg SP, McCann D, Desai M, Rosenbaum M, Leibel RL, Ferrante AW Jr: Obesity is associated with macrophage accumulation in adipose tissue. J Clin Invest 2003;112:1796-1808.

12 Wiecek A, Kokot F, Chudek J, Adamczak M: The adipose tissue: a novel endocrine organ of interest to the nephrologist. Nephrol Dial Transplant 2002;17:191-195.

13 El-Agroudy AE, Wafa EW, Gheit OE, Shehab el-Dein AB, Ghoneim MA: Weight gain after renal transplantation is a risk factor for patients and graft outcome. Transplantation 2004;77:1381-1385.

14 Teplan V, Schück O, Racek J,Lecian D, Haluzik M, Kudla M, Vitko S: Asymmetic dimethylarginine in obesity after renal transplantation. J Ren Nutr 2008;18:513-520.

15 Armstrong KA, Campbell SB, Hawley CM, Nicol DL, Johnson DW, Isbel NM: Obesity is associated with worsening cardiovascular risk factor profiles and proteinuria progression in renal transplant recipients. Am J Transplant 2005;5:2710-2718.

16 Mittermayer F, Pleiner J, Krzyzanowska K, Wiesinger GF, Francesconi M, Wolzt M: Regular physical exercise normalizes elevated asymmetrical dimethylarginine concentrations in patients with Type 1 diabetes mellitus. Wien Klin Wochenschr 2005;117:816-820.

-17 Teplan V, Mahrová A, Svagrova K, Racek J, Gürlich R, Teplan V Jr, Senolt L, Stollova M: Regular exercise training decreases asymmetric dimethylarginine after kidney transplantation. Vnitr Lék 2012;58:640-646.

$\checkmark 18$ Niebauer J, Clark AL, Webb-Peploe KM, Boger R, Coats AJ: Home-based exercise training modulates prooxidant substrates in patients with chronic heart failure. Eur J Heart Fail 2005;7:183-188.

-19 McLaughlin T, Stühlinger M, Lamendola C, Abbasi F, Bialek J, Reaven GM, Tsao PS: Plasma asymmetric dimethylarginine concentrations are elevated in obese insulin-resistant women and fall with weight loss. J Clin Endocrinol Metab 2006;91:1896-1900.

20 Tarnow L, Hovind P, Teerlink T, Stehouwer CD, Parving HH: Elevated plasma asymmetric dimethylarginine as a marker of cardiovascular morbidity in early diabetic nephropathy in type 1 diabetes. Diabetes Care 2004;27:765-769.

21 Achan V, Broadhead M, Malaki M, Whitley G, Leiper J, MacAllister R, Vallance P: Asymmetric dimethylarginine causes hypertension and cardiac dysfunction in humans and is actively metabolized by dimethylarginine dimethylaminohydrolase. Arterioscler Thromb Vasc Biol 2003;23:1455-1459. 


\section{Kidney \\ Blood Pressure Research}

Kidney Blood Press Res 2014;39:289-298

DOI: 10.1159/000355806

Published online: August 27, 2014

(C) 2014 S. Karger AG, Basel

www.karger.com/kbr Obesity

22 Ogawa T, Kimoto M, Sasaoka K: Purification and properties of a new enzyme, NG,NG-dimethylarginine dimethylaminohydrolase, from rat kidney. J Biol Chem 1989;264:10205-10209.

-23 Kimoto M, Tsuji H, Ogawa T, Sasaoka K: Detection of NG,NG-dimethylarginine dimethylaminohydrolase in the nitric oxide-generating systems of rats using monoclonal antibody. Arch Biochem Biophys 1993;300:657-662.

-24 Zaletel J, Cerne D, Lenart K, Zitta S, Jurgens G, Estelberger W, Kocijancic A: Renal functional reserve in patients with Type 1 diabetes mellitus. Wien Klin Wochenschr 2004;116:246-251.

-25 Fukai T, Siegfried MR, Ushio-Fukai M, Cheng Y, Kojda G, Harrison DG: Regulation of the vascular extracellular superoxide dismutase by nitric oxide and exercise training. J Clin Invest 2000;105:1631-1639.

-26 Lin KY, Ito A, Asagami T, Tsao PS, Adimoolam S, Kimoto M, Tsuji H, Reaven GM, Cooke JP: Impaired nitric oxide synthase pathway in diabetes mellitus: role of asymmetric dimethylarginine and dimethylarginine dimethylaminohydrolase. Circulation 2002;106:987-992.

27 Sciaqua A, Candigliota M, Ceravolo R, Scozzafava A, Sinopoli F, Corsonello A, Sesti G, Perticone F: Weight loss in combination in human obesity. Diabetes Care 2003;26:1673-1678.

28 Paiva H, Lehtimaki T, Laakso J, Ruokonen I, Tervonen R, Metso S, Nikkilä M, Wuolijoki E, Laaksonen R: Dietary composition as a determinant of plasma asymmetric dimethylarginine in subject with hypercholesterolemia. Metabolism 2004;53:1072-1075.

29 Mittermayer F, Mayer BX, Meyer A, Winzer C, Pacini G, Wagner OF, Wolzt M, Kautzky-Willer A: Circulating concentrations of asymmetrical dimethyl-L-arginine are increased in women with previous gestational diabetes. Diabetologia 2002;45:1372-1378.

-30 Paiva H, Lehtimaki T, Laakso J, Ruokonen I, Rantalaiho V, Wirta O, Pasternack A, Laaksonen R: Plasma concentrations of asymmetric-dimethyl-arginine in type 2 diabetes associate with glycemic control and glomerular filtration rate but not with risk factors of vasculopathy. Metabolism 2003;52:303-307.

-31 Ito A, Egashira K, Narishige T, Muramatsu K, Takeshita A: Renin-angiotensin system is involved in the mechanism of increased serum asymmetric dimethylarginine in essential hypertension. JPN Circ 2001;65:775-778.

-32 Boots JM, Christiaens MH, van Hoof JP: Effect of immunosuppressive agents on long-term survival of renal transplant recipients: focus on the cardiovascular risk. Drugs 2004;64:2047-2073.

-33 Oflaz H, Turkmen A, Kazancioglu R, Kayacan SM, Bunyak B, Genchallac H, Erol B, Mercanoglu F, Umman S, Sever MS: The effects of calcineurin inhibitors on endothelial function in renal transplant recipients. Clin Transplant 2003;17:212-216.

-34 Teplan V, Malý J, Gürlich R, Teplan V, Jr, Kudla M, Pit’ha J, Racek J, Haluzík M, Šenolt L, Štollova M: Muscle and fat metabolism in obesity after kidney transplantation:no effect of peritoneal dialysis or hemodialysis. J Ren Nutr 2012;22:166-170.

35 Sharma AM, Chettey VT: Obesity, hypertension and insulin resistance. Acta Diabetol Lat 2005;42:S3-S8. 